\title{
Aeropalynologic Features of Plants and Fungi Pollination in Kazan and Their Influence on Hay Fever
}

\author{
Rakhim Khamitov, Rafcat Kireev \\ Lyceum boarding school No:2, Shamilya Usmanova 9, Kazan, 420095, Russia; RKhamitov2016@litsey2.ru
}

ABSTRACT: The greatest cause of respiratory allergens related to human exposure to biological and chemical components is atmospheric air, which has powerful sensitizing agents. ${ }^{1}$ Among the large number of stimuli, it is the pollen and fungal spores that most frequently exacerbate hay fever. The objective of this study is the identification of impact on the human body by the pollen of various plants. This task involves aeropalynology monitoring, enabling assessment and prediction of the environment, and is aimed at the timely correction of treatment of allergic diseases in patients. In this study we observed the pollen of different plants with help of hand-made device. In the end of our review we found that the problem is very relevant, and we need to help people with allergies from pollen. In the future we are planning to make a convenient app which will help people with allergies in identifying the most dangerous zones and times.

KEYWORDS: Ecology; health; allergies; monitoring; pollen; pollinosis; aeropalynologic features.

\section{- Introduction}

The importance of pollen monitoring is growing more and more due to the prevalence of diseases caused by allergies, environmental deterioration, and need for the development of effective drugs for fighting allergic reactions. However, in Russia, pollen monitoring is carried out partially and non-regularly in certain regions. This does not allow one to see the whole picture across the country, as the available data is clearly insufficient. The importance of local information for regional studies is high, since this data has a substantial informational value given the regional nature of hay fever. ${ }^{2}$

Pollen allergy (pollinosis) is a classic allergic disease, the clinical manifestations of which are allergic inflammation that arises in response to pollen allergens. Due to global climate change, changes in nutrition and the way of our life, and air pollution, the number of people suffering from allergic diseases is increasing. ${ }^{3}$

For pollen monitoring and interpretation, it is also important to take into account that the pollen of plants is of differing in size, and the presence or absence of grooves spines, and outgrowths. On such grounds, pollen identification is carried out. For instance, when a pollen grain with a diameter of 60 to 100 microns is inhaled, it settles on the mucosa of the upper respiratory tract, while one with a diameter of 20-30 microns penetrates the bronchial mucosa. ${ }^{4}$

Pollen of angiosperms - birch, alder and hazel, ash, maple, linden, oak, willow, etc., has a much stronger allergen activity. Pollen of birch has the most pronounced activity, since its content in the air is quite high, often: 20,000 pollen grains in 1 $\mathrm{m}^{3}$. It should be noted that most species of willows and limes are insect-polluted plants and they also produce a lot of pollen, which contributes to the emergence of allergies. ${ }^{5}$

The composition of the pollen of some tree species has the same protein complexes, which is the reason for the formation of common allergenic properties and cross allergies. For exam- ple, people suffering from birch hypersensitivity to pollen can simultaneously react to the pollen of hazel and alder. ${ }^{6}$

The allergy to pollen of woody plants affects more people in cities than in rural areas, where the concentration of pollen is several times higher. Numerous scientific findings indicate that pollen in cities is covered with a layer of pollution from the environment. These pollutants include carbon dioxide $\left(\mathrm{CO}_{2}\right)$, and various petroleum products which makes the pollen more allergenic. According to another scientific study, the reaction of the immune system in a polluted environment is stronger than in ecologically clean areas. ${ }^{7}$

Researchers also note that the prevalence of sensitization to birch pollen in Europe. According to allergic survey data, birch pollen concentrations also vary significantly: from 5\% in the Netherlands to 54\% in Switzerland. Even in Northern Italy, the share of positive allergic tests has increased, which is associated with the increased popularity of birch as an ornamental plant in this area. In addition, there is evidence of a significantly stronger allergenicity of pollen from trees grown at elevated temperatures. ${ }^{8}$

This study covers the regional aspect of the fungal and plant pollination features and presents the results of conducted pollen monitoring in the city of Kazan in the Republic of Tatarstan. The data obtained during the research, with the further development of pollen monitoring programs, will create a network of observation stations for the maximum coverage of Russia's regions and the development of an effective forecast system.

\section{- Results and Discussion}

Pollen monitoring is a unique interdisciplinary project that is being conducted in some regions of Russia. Data on monitoring conducted in Samara, Saratov and other cities has been recorded. The pollen monitoring has been developed together with specialists from the Russian Association of Allergists and 
Clinical Immunologists (RAAKI), the Moscow State University, and the pharmaceutical company Takeda.

Thus, data collected in the framework of dust monitoring for five groups of plants allow us to conclude that the most intensive pollination in Kazan is observed in groups of mushrooms, weeds and coniferous trees. In all groups, the greatest intensity is from May to September, with coniferous and deciduous trees being the most active in May, cereals in June, and weeds and fungi in July and August (Tables 1-3).

The highest intensity transfer of pollen occurs in the daytime (from 5 to 11 a.m.), while at night the intensity of pollination is minimal. In this case, the exacerbation of pollinosis occurs at a time when the concentration of pollen in the air already has threshold values: $10-20$ pollen grains per $1 \mathrm{~m}^{3}$ of air.

Consider the data of our pollen monitoring in Kazan by groups.

\section{Group I - Deciduous trees:}

This group includes the following plant names: birch, elm, oak, willow, maple, linden, alder, hazel, poplar.

Table 1: Data of pollen monitoring by deciduous trees, p.g. The greatest intensity is from May to September.

\begin{tabular}{|c|c|c|c|c|c|c|c|}
\hline \multirow{2}{*}{$\begin{array}{c}\text { Plant } \\
\text { specimen }\end{array}$} & \multicolumn{2}{|c|}{2016} & \multicolumn{6}{c|}{2017} \\
\hline & May & June & April & May & June & July & August \\
\hline Birch & 327 & 4 & 18,43 & 153,26 & 95,18 & & \\
\hline Elm & & & & & 16,49 & & \\
\hline Oak & & & & 555 & & & \\
\hline Willow & & & & & 0,97 & & \\
\hline Maple & 7 & & 0,97 & & 0,97 & & \\
\hline Linden & 1 & 153 & & & 94,09 & 146,35 & 5,8 \\
\hline Alder & & & 12,61 & & & & \\
\hline Hazel & & & & & 0,97 & & \\
\hline Poplar & 4,97 & & 1,94 & 0,97 & 1,94 & & \\
\hline
\end{tabular}

(All numbers are shown in p.g./ $\mathrm{m}^{3}$ )

According to the data, it is evident that the highest activity of pollen emissions was recorded in the birch, maple, and linden trees. Although many researchers agree that the most allergenic trees are considered to be maple, hazel, alder, birch and ash, and the majority of patients with pollinosis consider poplar to be their main enemy. In our study the highest pollination value was observed in birch. It is this deciduous plant that is the most dangerous causative agent of pollinosis. The distribution according to tree types is shown in (Figure 1)

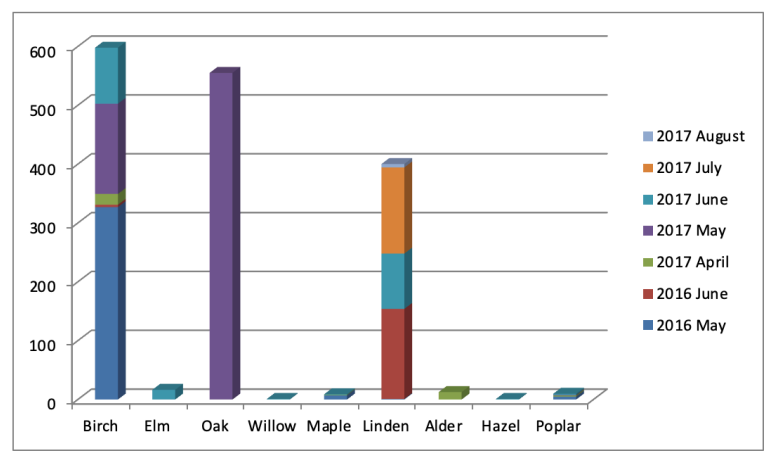

Figure 1: Pollen monitoring data by types of deciduous trees.

For an allergy sufferer, the place of residence is of paramount importance. It is better to live in a locality with a predominance of coniferous trees.
The distribution of the intensity of pollination of deciduous trees by months is shown in the graph (Figure 2).

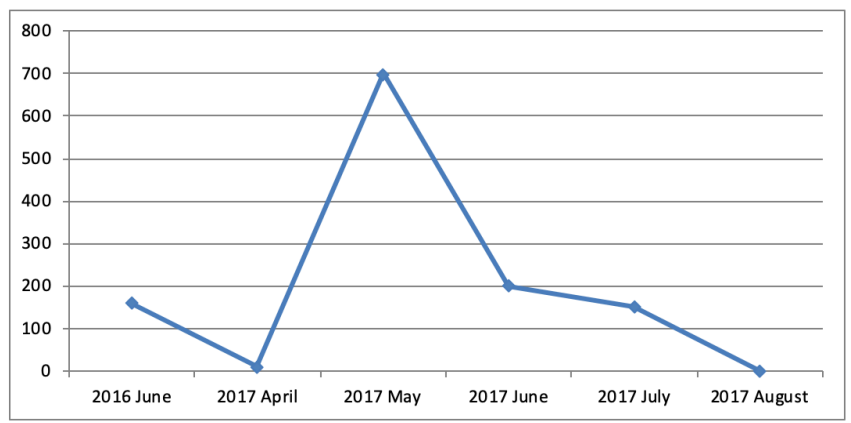

Figure 2: Data from pollen monitoring of deciduous plants, p.g. (monthly).

The largest release of pollen in combination with deciduous trees occurs at the end of spring and early summer. The maximum pollination occurs in mid-May.

\section{Group II - Coniferous trees:}

Group II is represented by coniferous trees: pine (Pínus) and spruce (Pícea).

The period of pollination the pine is 2 months - from April to May. Ate - only one month - May. The pollination of the pine is shown in Figure 3.

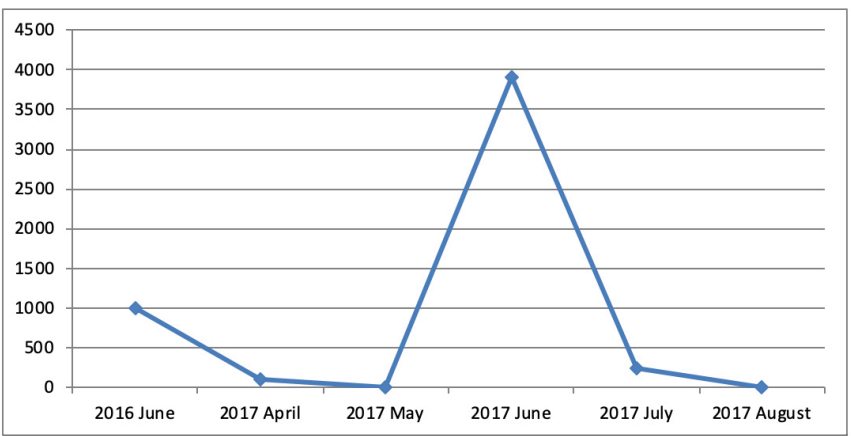

Figure 3: Data of pollen monitoring of pine, p.g. The greatest intensity is from May to September.

According to the data it can be seen that the greatest pollination occurs in May.

Let us consider in detail the dynamics of pollination in May for 2016 and 2017 (Figures 4 and 5).

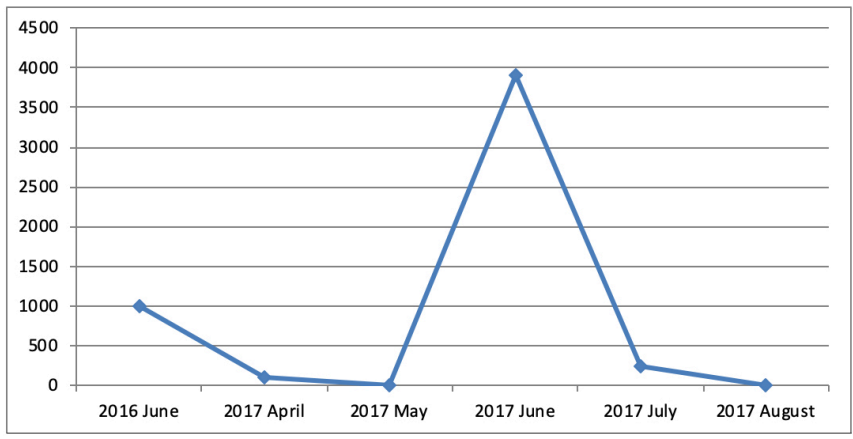

Figure 4: Dynamics of pine pollination in May 2016, p.g./ $\mathrm{m}^{3}$.

It can be seen from the graphs that the highest intensity of pollination occurs in the first ten days of the month. Then, 
from the middle of May, the intensity of pollination gradually decreases.

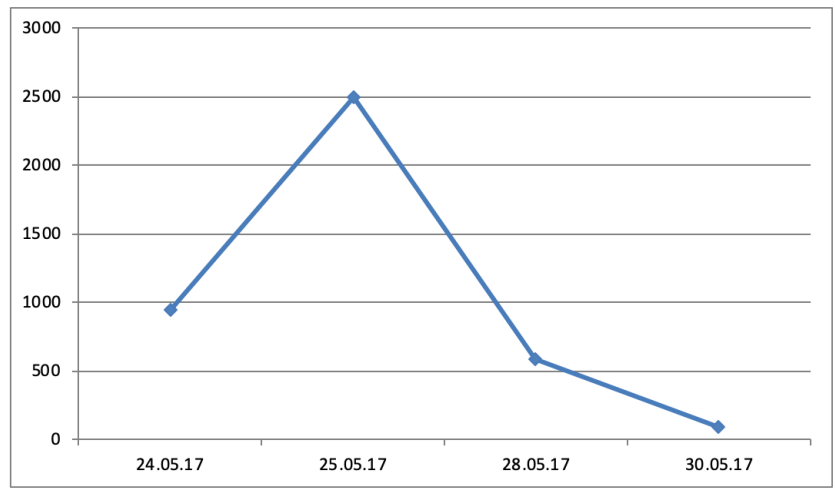

Figure 5: Pollen monitoring of the pine for May 2017, p.g. $/ \mathrm{m}^{3}$.

For spruce, the pollen indicators in May 2016 and 2017 are as follows by day (Figure 6).

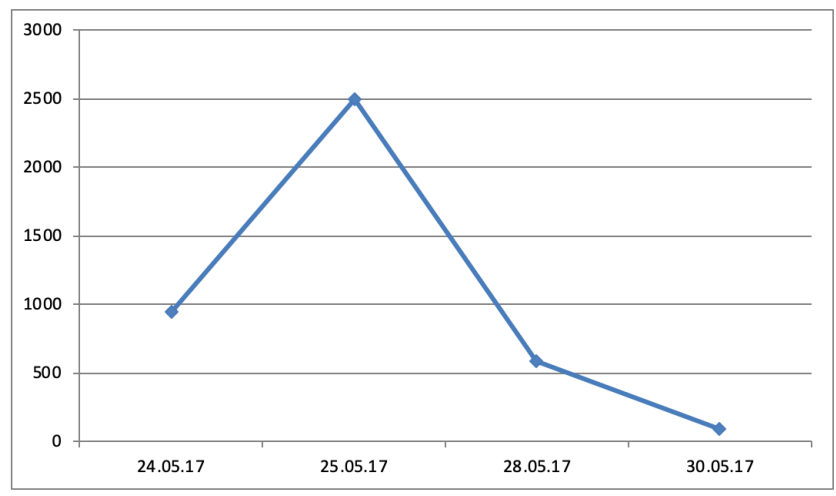

Figure 6: Pollen monitoring of spruce for May 2016, p.g. / m³.

Thus, in spruce and pine trees there is an increase in the intensity of pollination in mid-May and a decrease by the end of the month. For allergy sufferers, the pollen of coniferous trees is not as dangerous as that of deciduous trees, because its allergenicity is low due to their large diameter (30 microns). However, gymnosperms produce a lot of pollen, so sensitivity to it is still present. In the European part of Russia, coniferous trees that most often causes allergies are spruce and pine. ${ }^{9}$

\section{Group III-Mushrooms.}

The cause of an allergic reaction is the ingress of microorganisms into irritated nasal mucosa, which cause plant diseases, for example, mold fungi. Common species of mushrooms of the genera Cladosporium and Alternaria, represent a certain danger when spores are actively detected in the air - from March to November.

Manifestations of an allergy of this origin are expressed in the diseases - dermatitis, hives, eczema, allergic rhinitis, conjunctivitis, and bronchial asthma. Fungal spores can form eosinophilic infiltrates in the lungs and are visible on an X-ray image as small blackouts. When detecting the sensitivity of mucous to fungal spores, signs of allergy can be identified after contact with raw, musty grass and hay, after staying in rooms with increased dampness and affected by mold, and also when eating foods fermented during cooking - such as sauerkraut and kvass. From May to November, the danger of getting an allergy to fungal spores increases to one hundred percent.

Data on the intensity of dust mushrooms of the genus Cladosporium, Alternaria collected during the period from April to September 2017 is shown in Figure 7.

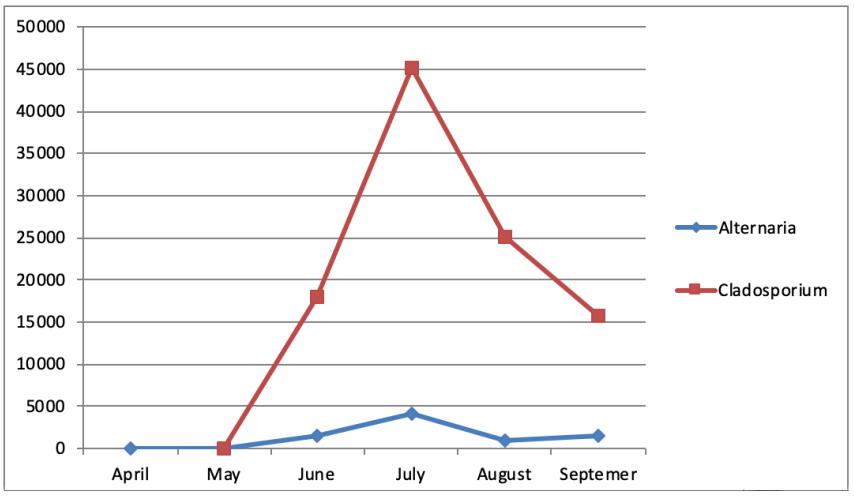

Figure 7: Data from the pollen monitoring of the alternative and Cladosporium for the period from April to September 2017, p.g.

According to the monitoring data, it can be concluded that the greatest activity is from Cladosporium, and the greatest peak of pollination intensity occurs in the summer months, most notably in July.

Furthermore, the increase in the intensity of dust begins in May and ends in July, and the decline occurs until September.

The intensity of pollination of the Cladosporium by months is shown in Figure 8.

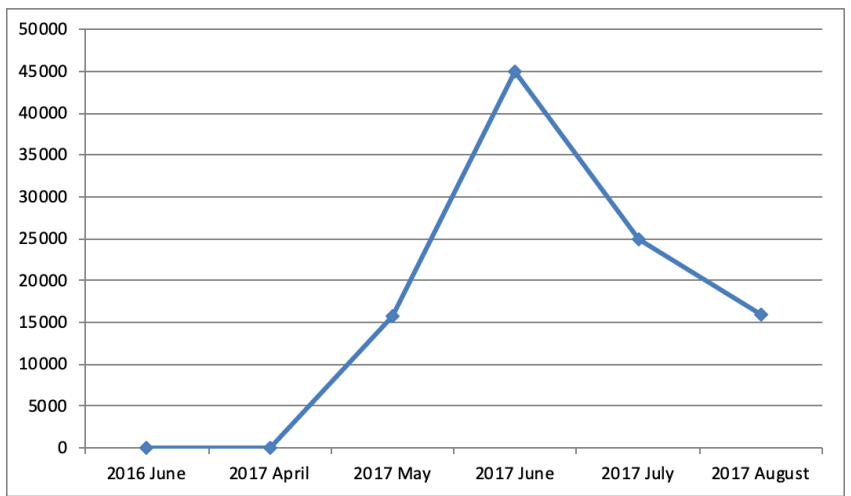

Figure 8: Data of pollen monitoring of the cadozporium for the period from April to September 2017, p.g.

Infection usually occurs on weakened or dying plants, primarily as a result of the diseases at the base of the stem, caused by the yellow dwarf virus, as well as partial felopopulosis due to fusariosis. If during the ripening there are prolonged rains, there is a strong infection.

Secondary fungi also inhabit areas of necrosis on leaves arising from mechanical damage (hail, spring harrowing of winter crops), or due to the erosion of leaves with solutions of nitrogen fertilizers, slurry, herbicides.

\section{Group IV-Cereals.}

Allergy to cereals is the most common of all the major types. According to statistics, one in 200 people has an allergy to cereals. This disease can lead to problems, because many foods 
contain flour or flour products such as pasta and confectionery. There are several reasons for the occurrence of such an allergy

- impact on the organism of pollen of cereals;

- proteins contained in the plant can cause food allergies;

- gluten, contained in cereals, can cause the appearance and development of gluten enteropathy, which is a complication of the disease.

The pollen monitoring data for cereals is shown in the graph

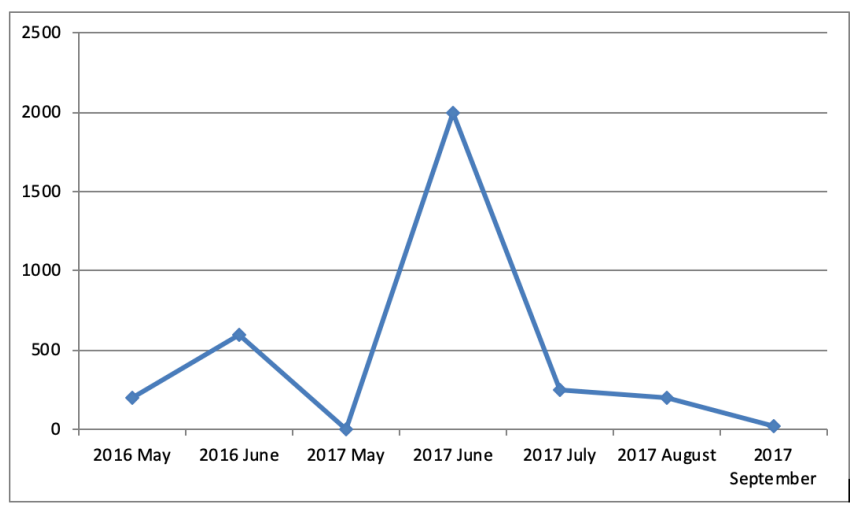

Figure 9: Data of pollen monitoring of the cadozporium for the period from April to September 2017, p.g.

(Figure 9).

The data shows that the greatest activity of the cereal allergen in Kazan falls on June. This is confirmed by the results of pollen monitoring for 2016 and 2017. The increase in the intensity of pollination occurs from May to June, while the intensity decreases from the end of June to September. From July to September, the intensity of pollination is low. The conservation or sometimes even the resumption of pollination of cereals in the second half of the summer is due to the growth of cereals after mowing.

Group V-Weeds.

This group is represented by weed plants, namely of the genera Ruhmex, Plantágo, Ambrosia, Chenopodioídeae, Artemisia and Urtíca. Pollen monitoring data for a group of weed plants were collected from May to June 2016 and from May to September 2017. The results are shown in Table 2.

Table 2 pollination of a group of weed plants in 2016-2017. Graphical change in the dynamics of pollination by weed plants is shown in Figure 10.

Table 2: Table 2 pollination of a group of weed plants in 2016-2017.

\begin{tabular}{|c|c|c|c|c|c|c|c|}
\hline \multirow{2}{*}{$\begin{array}{c}\text { Plant } \\
\text { Specimen }\end{array}$} & \multicolumn{2}{|c|}{2016} & \multicolumn{5}{|c|}{2017} \\
\hline & May & June & April & May & June & July & August \\
\hline Ambrosia & & & & & & 6,88 & 52,44 \\
\hline Nettle & & 23 & 8.73 & $\begin{array}{c}2054, \\
5\end{array}$ & $\begin{array}{c}2911, \\
9\end{array}$ & $\begin{array}{c}791,6 \\
7\end{array}$ & 6236 \\
\hline Mare & & 85 & & 74,09 & $\begin{array}{c}330,1 \\
8\end{array}$ & 217,3 & 58,32 \\
\hline Plantain & & 4 & 74,69 & $\begin{array}{c}1599, \\
5\end{array}$ & $\begin{array}{c}1234, \\
2\end{array}$ & $\begin{array}{c}666,0 \\
5\end{array}$ & 22,44 \\
\hline Sagebrush & & 1 & & & $\begin{array}{c}117,6 \\
7\end{array}$ & $\begin{array}{c}460,7 \\
2\end{array}$ & 146,88 \\
\hline Sorrel & 5 & 9 & & $\begin{array}{c}362,7 \\
6\end{array}$ & $\begin{array}{c}125,5 \\
5\end{array}$ & $\begin{array}{c}164,0 \\
7\end{array}$ & \\
\hline
\end{tabular}

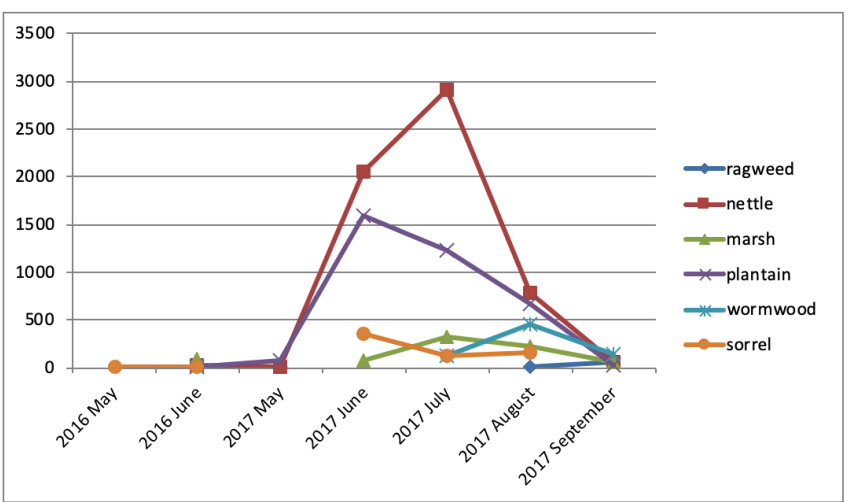

Figure 10: Data of pollen monitoring of weeds for the period from May to June 2016 and from May to September 2017, p.g..

According to the data, in most plants of the weed group, the greatest intensity of pollination occurs during the period from May to September, with a peak in June-July. In addition, for some plants (for example, wormwood), the peak intensity of pollination falls on August.

The greatest pollination among weed plants during the indicated period was observed in nettle and plantain. Consider the dynamics of pollination of these plants in more detail (Figures 11 and 12).

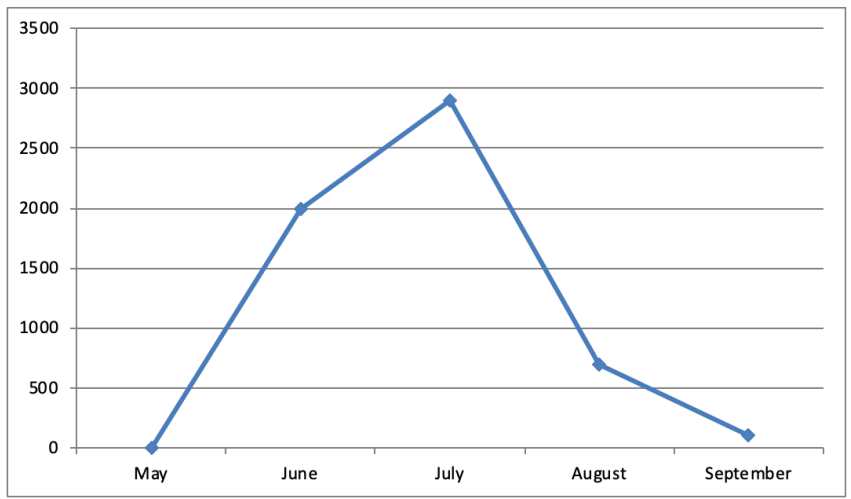

Figure 11: Dynamics of nettles pollination (2017), p.g.

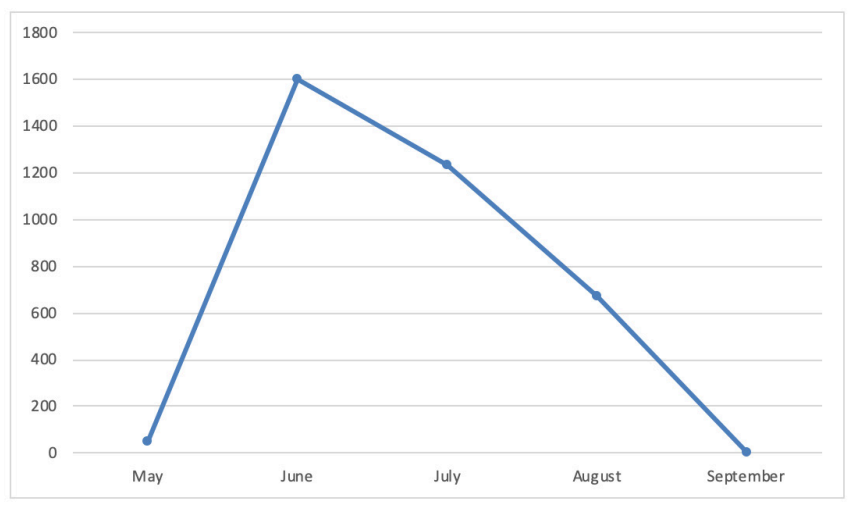

Figure 12: Dynamics of plantain pollination (2017), p.g.

The intensity of nettles pollination tends to increase in the period from May to July 2017 and to decrease from July to September. The occurrence of allergies occurs during a period when pollen, actively floating in the air, settles in the mucous 
membrane of the nose, falls into the eyes and mouth, penetrates into the bronchi, and has contact with the skin.

The intensity of the plantain pollination is accompanied by a shorter period of growth, from May to June, and at the end of June growth decreases noticeably, and the fall in the degree of pollination stretches from the end of June to September.

Summary data for all plants included in pollen monitoring during the period under review are presented in Table 3.

Table 3: Consolidated results of pollen monitoring for all groups of plants and fungi.

\begin{tabular}{|c|c|c|c|c|c|c|c|c|}
\hline \multirow[b]{2}{*}{ Plant family } & \multicolumn{2}{|c|}{2016} & \multicolumn{6}{|c|}{2017} \\
\hline & May & June & April & May & June & July & August & September \\
\hline $\begin{array}{c}\text { Deciduous } \\
\text { trees }\end{array}$ & 891 & 157 & 33,95 & 154,23 & 206,61 & 146,35 & 5,8 & \\
\hline $\begin{array}{c}\text { Coniferous } \\
\text { trees }\end{array}$ & 1174 & 86 & 2,91 & 3901,34 & 229,89 & 0,97 & & \\
\hline Mushrooms & & & 0,97 & 142,59 & 19559,07 & 49409,81 & 26074,12 & 17333,28 \\
\hline Cereals & 236 & 627 & & 27,16 & 2010,77 & 242,56 & 177,76 & 32,76 \\
\hline Weeds & 5 & 122 & & 83,42 & 4088,86 & 4719,47 & 2306,69 & 342,44 \\
\hline
\end{tabular}

Graphical dynamics for the families of plants and fungi is presented in Figures 13 and 14.

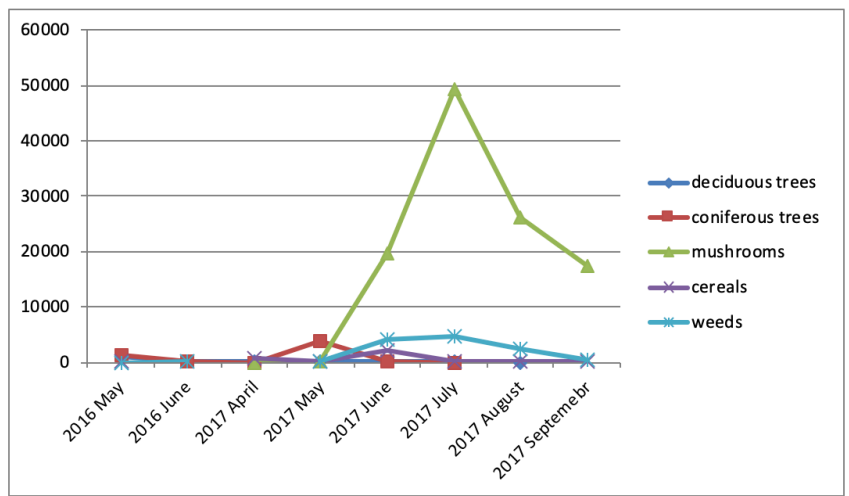

Figure 13: Summary dynamics of pollination in all plant groups for 2016 and 2017, p.g.

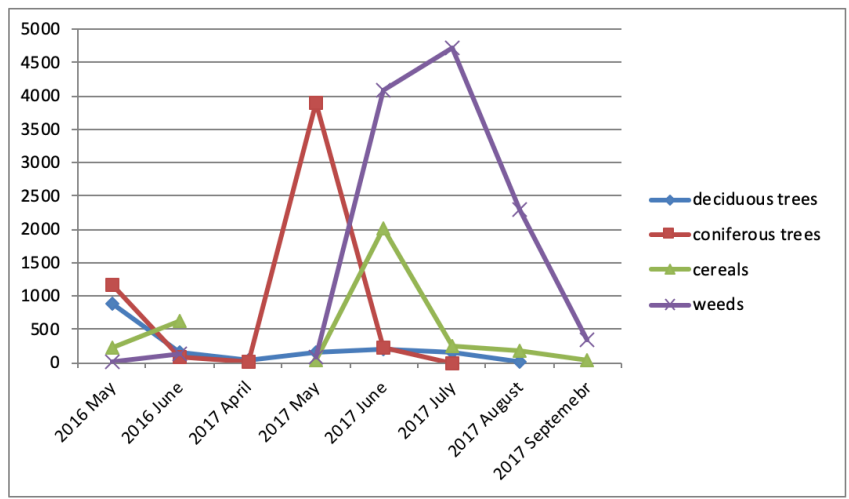

Figure 14: Summary dynamics of pollination in all plant groups for 2016 and 2017, p.g.

Thus, data collected in the framework of dust monitoring for five groups of plants allow us to conclude that the most intensive pollination in Kazan is observed in the groups of mushrooms, weeds and coniferous trees. In all groups, the greatest intensity is from May to September, with coniferous and deciduous trees being the most active in May, cereals in June, and weeds and fungi in July and August.

\section{Conclusion}

The pollen monitoring that was carried out in the city of $\mathrm{Ka}-$ zan makes it possible to accurately record the initial and peak flowering periods of the plants in the region and to interpret the data on pollen monitoring more accurately. We plan to use the results obtained to inform the public through the resources of our pollen monitoring website.

The monitoring results make it possible to compile plant and fungal pollination calendars for a region, as well as to reveal how pollination of various plant and fungi species increases pollinosis and other allergies in people. These calendars are an effective tool to create appropriate medications for the prevention and treatment of allergic diseases.

Our study increases the opportunities for Kazan scientists to regularly study the qualitative and quantitative composition of the spore-pollen spectrum of the surrounding air. It also allows for dynamic real-time corrections of the calendar and plant dust maps, leading to a higher degree of certainty in predicting the health status of sensitized patients.

According to the analysis of the results, in Kazan there is a high risk of having an allergic reaction to the pollen of mushrooms (of the genus Cladosporium), weeds (nettles and plantain), and conifers, and a low risk of allergic reaction from the pollen of deciduous trees: elm, willow, maple, alder, hazel and poplar.

Seasonal pollen allergy to flowering plants (pollinosis) is a very common disease that can present in both adults and young children. The best solution is to avoid contact with the allergen. During the time of flowering, some people may leave to regions where the allergy-inducing plant is not common, for example, in the foothills or to places with colder climates. However, circumstances don't always allow for those with allergies to just leave, so alternative solutions should be explored.

Pollen monitoring plays an equally important role in environmental studies. As a biological indicator, pollen can be used to assess the environmental situation. Under the influence of air and soil pollution, the properties and quality of pollen change (in particular, sterile or mutant pollen grains can appear).

Thus, the aeropalinological features of pollination may have seasonal differences in the clinical signs of pollen. The duration of the symptoms may depend on the duration of the main period of pollination, and the intensity (The concentration of pollen). The nature of the dependencies of different combinations of factors among themselves continues to be studied at the present time. Epidemiological studies require a more detailed and long-term study.

\section{Methods}

The purpose of the study is to identify the aeropalinological features of plants and fungi pollination in Kazan, namely certain species of deciduous and coniferous trees, fungi, grasses, and weeds - by interpreting the results of pollen monitoring conducted in Kazan during two seasons (2014 - 2015 and 2016 - 2017), as well as a comparison of plant species and their periods of maximum pollination in order to determinethe effect of these plants and fungi species on the increase of pollinosis. 
In Kazan, during the two seasons mentioned above, monitoring work was conducted with the use of a pollen trap. The hand-made pollen trap device was installed on the roof of the Institute of Fundamental Medicine and Biology at Karl Marx Str., 74, at 10 meters above ground.

Thus, within the given period, data from pollen of twenty plants and fungi specimen were collected. This data made it possible to reveal the regularities and peculiarities of their pollination process.

A tape was fixed with a special silicone solution that was attached to the drum of the device so that the pollen could stick better. The drum functioned due to a clockwork mechanism installed in it, that started periodically. After removal, the tape was cut into seven parts (depending on how many days passed) and stained with a special dye, to which only the shell of plant pollen and fungal spores reacted. Preparations were viewed by transects, and the amount was multiplied by a correction factor (0.97).

Palynological analysis is based on differences in the morphological structure of pollen grains and spores of different plant species. Important characteristics for analysis are the size and shape of pollen grains and spores, the types of apertures and their number, and the types of sculpture and texture.

Aeropalanological studies are conducted by collecting pollen from plants and spores of fungi contained in the air, identifying them, quantifying them by visual counting in the field of view of the microscope, and developing pollination calendars.

At present, there are no universal snares suitable for the study of all types of biological particles. Each area of research (palynology, mycology, virology, etc.) requires its own methods of sampling, subsequent processing and identification of the material. Two principles are used for trapping biological particles: gravity (gravitational particles suspended in the air are precipitated by gravity on a horizontal surface) and impact/ collision (the particles suspended in air move together with the air flow and settle on the surfaces of various types materials and orientations). Biological particles, in turn, are natural (by means of wind) or artificially created (different pumps). Most of the impact traps belong to the volumetric type, in which the air flow is created forcibly, due to the operation of the air pump.

The latter method, along with the analysis of the total content of pollen in the air, makes it possible to estimate the daily rhythms of pollination of individual plants.

The importance of monitoring assumes that the type of pollen that causes allergies emanates from trees, grass, and weeds, where fruits or flowers are usually not visible. On such plants there are many small, light granules of dry pollen, which is very quickly spread through the air. The general characteristic of plant allergens is given in Table 4.

As an object for the analysis within this pollen monitoring, 20 plants were selected in the following groups:

1. Group: "Deciduous trees" - birch, elm, oak, willow, maple, linden, alder, hazel, poplar.

2. Group: "Coniferous trees" - spruce and pine.

3. Group: "Mushrooms" - alternarium, cladosporium.

4. Group: "Weeds" - ragweed, nettle, stink, plantain, wormwood, sorrel.
5. Group: "Cereals".

Table 4: General Species Characteristics of Allergen Plants.

\begin{tabular}{|l|l|}
\hline Plant species & \multicolumn{1}{|c|}{ Subspecies } \\
\hline Weeds & $\begin{array}{l}\text { Ambrosia wormwood, wormwood, shirits (plant of the family } \\
\text { amaranth), white mar, marsh, tumbleweed (Russian solyanka - } \\
\text { Salsola ruthenica), plantain lanceolate (Plantago lanceolata). }\end{array}$ \\
\hline Cereals & $\begin{array}{l}\text { Timothy-grass (Phleum pratense), Kentucky bluegrass (Roa } \\
\text { family grass), sorghum (Sorghum), porcine palmate, white grass } \\
\text { (Agrostis alba), hedgehog (Dactylis glomerata), ylang-ylang, } \\
\text { perennial darnel, uniola ears, bukharnik woolly (Holcus lanatus) } \\
\text { and fescue (Festuca). }\end{array}$ \\
\hline $\begin{array}{l}\text { Deciduous } \\
\text { perennial trees }\end{array}$ & $\begin{array}{l}\text { Oak, ash, elm, birch, maple, alder, hazelnut, as well as hickory } \\
\text { (genus of the North American hazel), walnut pits, boxwood } \\
\text { evergreen, Mexican juniper. }\end{array}$ \\
\hline
\end{tabular}

It is also necessary to note the features that allowed researchers to make a high-quality pollen monitoring. First, pollen concentration in the atmosphere is related to air temperature, atmospheric pressure, wind speed, and even the time of day. The concentration of pollen largely determines the intensity of the allergic reaction. In dry, warm weather, plants begin to dust more intensively than on cold, rainy days, but the period of flowering of plants during the cold period is prolonged. Windless weather also prevents the transfer of pollen.

\section{Acknowledgement}

The work was performed under the guidance of the biology teacher Malikova Farida and the biology teacher and supervisor Mirsaitov Nail.

\section{References}

1. Klymenko V.A., Karpushenko J.V., Servetnik A.V., Optimization of the laboratory diagnosis of allergies with regard to regional peculiarities; Clinical Pediatrics 2015 No6 (66).

2. Statistics in Russia, the main cause of pollinosis. URL:http://allergy-mask.ru/articles/allergiyastatistika-v-rossii.html ; (date of the application: 26.09.2020).

3. Pollen allergy symptoms and treatment.

URL:https://allergen-net.ru/allergiya-na-pylcusimptomy-i-lechenie.html ;

(date of the application: 26.09.2020).

4. All about pollen allergy.

URL: https://dompchel.ru/zdorove/allergiya/na-pyltsu/ \#i-9; (date of the application: 26.09.2020).

5. Plant pollen: when does it appear, where and in what quantity? URL: https://prosimptom.ru/a-z/pylca. html\#literature ; (date of the application: 27.09.2020).

6. Khutueva S.K., Fedoseeva V. N. Aeroallergens, allergen nomenclature. URL: https://medbe.ru/materials allergeny/aeroallergeny-nomenklatura-allergenov/ ?PAGEN_2=2 ; (date of the application: 27.09.2020).

7. Allergenic activity of pollen of some plants.

URL: https://studbooks.net/911345/estestvoznanie/ allergennaya_aktivnost_pyltsy_nekotoryh_rasteniy ; (date of the application: 27.09.2020)

8. Sofiev M., Berger U. et al. MACC regional multimodel ensemble simulations of birch pollen dispersion in Europe. 23 Jul 2015. URL: https://acp.copernicus.org/ 
articles/15/8115/2015/ ; (date of the application: 27.09.2020).

9. Flowering calendar. URL: https://www.letograf.ru/

drugs/kalendar-pyleniya-derevev-v-moskve-kalendar-

creteniya/ ; (date of the application: 27.09.2020).

\section{- Author}

Rakhim Khamitov was born in Kazan, Tatarstan on the 7 th of September 2003. Rakhim entered the 2nd lyceum in 2016, and he is still studying there. He is keen on football (soccer), and also interested in chemistry.

Rafcat Kireev was born in Kazan, Tatarstan on April 25th, 2002. Studied at the 2 nd lyceum for 5 years, this year he has entered to the University-KFU Specialty-medical care. He is interested in fencing. 